\title{
KEMAMPUAN TANAMAN KARET DALAM MENURUNKAN KADAR DUST FALL DI SEKITAR JALAN ANGKUTAN BATUBARA
}

\author{
Vista Septiani Putri, Junaidi, Munawar Raharja \\ Poltekkes Kemenkes Banjarmasin Jurusan Kesehatan Lingkungan \\ Jl. H. Mistar Cokrokusumo No.1A Banjarbaru Kalimantan Selatan 70714 \\ E-mail: vsputri@gmail.com
}

\begin{abstract}
The Ability Rubber Plants in Lowering to Dust Fall Level Along the Coal Haul Road.Changes in air environment are generally caused by air pollution. Coal transportasion activity make the impact of air pollution such as dust fall along the coal haul road. A solution to handling dust fall along the coal haul road with vegetation of plant which have ability to reduce dust fall particles. The purpose of this research is to know the ability rubber plants in lowering the dust fall level along coal haul road. The benefit as raw material inputs in controlling of dust pollution in environment using berrier plant. The method of this research use a field experiment with design pretest and posttest with control group. The population of this research is the dust fall level and samples research is dust that measured on 4 location that represent the diffrences landscape $50 \mathrm{~m}$, $100 \mathrm{~m}, 150 \mathrm{~m}$ and $200 \mathrm{~m}$. Every width of landscape measure of 2 samples poin before and after of a landscape. It done in 5 times replicas.Data analysis using a simple regression. There is influence of rubber plant ability to decrease dust content to the distance determined with result of percentage of degradation of dust settled at 50 meter distance without barrier $48,0 \%$ to distance 50 meter with barrier $57,0 \%$.
\end{abstract}

Keywords: Level of Dust; Rubber Plant Barrier

\begin{abstract}
Abstrak: Kemampuan Tanaman Karet Dalam Menurunkan Kadar Dust Fall Di Sekitar Jalan Angkutan Batubara. Perubahan lingkungan udara pada umumnya disebabkan pencemaran udara.Aktivitas transportasi batubara memberikan dampak pencemaran udara berupa debu di sepanjang jalan angkutan batubara.Salah satucara penanganan debu di sepanjang jalan angkutan bautabara dengan vegetasi tanaman yang memiliki kemampuan mengurangi partikel debu. Tujuan penelitian ini mengetahui kemampuan tanaman karet (Hevea brasiliensis) dalam menurunkan kadar debu terendap (dust fall) di sepanjang jalan angkutan batubara, manfaat penelitian ini adalah sebagai bahan masukan dalam pengendalian pencemaran debu di lingkungan menggunakan barrier tanaman.Metode penelitian yang digunakan adalah eksperimen lapangan, dengan rancangan Pretest and Posttest with Control Group, populasi dalam penelitan ini adalah kadar debu terendap (dust fall), dan sampel pada 4 lokasi dan 2 titik dengan 5 kali pengulangan. Analisis data menggunakan uji regresi sederhana.Hasil penelitian menunjukan bahwa ada perbedaan antara kadar debu tanpa barrier dan kadar debu dengan barrier, ada pengaruh kemampuan tanaman karet dalam menurunkan kadar debu terhadap jarak yang ditentukan dengan hasil persentase penurunankadar debu terendap pada jarak 50 meter tanpa barrier 48,0 \% terhadap jarak 50 meter dengan barrier $57,0 \%$.
\end{abstract}

Kata kunci: Kadar Debu; Barrier Tanaman Karet

\section{PENDAHULUAN}

Pencemaran udara dapat diartikan sebagai adanya bahan-bahan asing atau zat-zat asing di udara dalam jumlah dan waktu tertentu yang menyebabkan perubahan komposisi udara, sehingga menimbulkan gangguan terhadap makhluk hidup dan barang-barang berharga lainnya. Salah satu bahan pencemar udara tersebut adalah debu[1].

Sektor transportasi memegang peran yang sangat besar dalam mencemari lingkungan dan aktivitas transportasi batubara dapat memberikan dam- 
pak pencemaran udara berupa debu di sepanjang jalan angkutan batubara[2]. Berdasarkan hasil studi menunjukkan bahwa konsentrasi debu terendap ini sangat tinggi, lebih dari 50 kali lipat dari baku mutu lingkungan yang ditetapkan untuk kawasan pemukiman maupun kawasan industri,

Salah satu cara penanganan dan pengendalian pencemaran udara berupa debu adalah dengan menggunakan vegetasi tanaman sebagai penghalang penyebaran debu untuk mengurangi polutan partikel debu di udara.

\section{BAHAN DAN CARA PENELITIAN}

Populasi penelitian ini adalah kadar debu terendap (dust fall) di sepanjang jalan angkutan batubara di Desa Tatakan Kabupaten Tapin. Pada penelitian ini sampel penelitian yang dimaksud dalam penelitian adalah debu yang terukur pada 4 lokasi penelitian yang mewakili perbedaan lebar lanskap yaitu $50 \mathrm{~m}, 100$ m, $150 \mathrm{~m}$ dan $200 \mathrm{~m}$. Setiap lokasi lebar lanskap diukur 2 titik sebelum dan setelah lanskap dan sebagai kontrol diukur pada lokasi tanpa adanya barrier tanaman karet[3], replikasi pada pene-litian ini dilakukan sebanyak 5 kali replikasi.

Teknik pengambilan sampel yang digunakan adalah metode pretest and posttest with control group. Bertujuan menunjukkan hubungan sebab-akibat dan melengkapi kelompok kontrol maupun pengukuran perubahan, tetapi juga menyertakan tes awal untuk menilai perbedaan antara dua kelompok[4]. Analisis data berupa analisis univariat dan analisis bivariat. Metode pengumpulan data penelitian ini dengan cara observasi dan pemeriksaan. Data sekunder yaitu suhu udara dan kelembaban udara.

Data yang diperoleh diolah secara manual, disajikan dalam bentuk tabel distribusi frekuensi. Untuk mengetahui kemampuan tanaman karet dalam menurunkan kadar dust fall di sekitar jalan angkutan batubara, dianalisis dengan menggunakan perhitungan statistik yaitu dengan bantuan komputer dengan Uji regresi sederhana.

\section{HASIL PENELITIAN DAN PEMBAHASAN}

Penelitian ini dilaksanakan hanya pada potongan ruas jalan berdasarkan: 1) keberadaan pemukiman penduduk, yang diasumsikan terdapat populasi manusia yang terpajan oleh debu dan 2) berdasarkan keberadaan kebun karet, yang diasumsikan akan terganggu pertumbuhannya. Lebar lanskap tanaman karet dilokasi penelitian sesuai dengan adanya kondisi di lapangan yang mempunyai jarak berbeda-beda yaitu 50 meter, 100 meter, 150 meter dan 200 meter.

Tabel 1. Hasil Pengukuran Kadar Debu Terendap Tanpa Barrier

\begin{tabular}{cccccccc}
\hline \multirow{2}{*}{ No } & Jarak dari & \multicolumn{4}{c}{ Kadar Debu Terendap (ton $/ \mathrm{km}^{2} /$ bulan) } & Rata- \\
& tepi jalan & P1 & P2 & P3 & P4 & P5 & rata \\
\hline 1 & $1 \mathrm{~m}$ & 481,26 & 532,35 & 575,05 & 558,73 & 509,62 & 531,40 \\
2 & $50 \mathrm{~m}$ & 266,95 & 298,86 & 258,14 & 260,40 & 289,18 & 274,71 \\
3 & $100 \mathrm{~m}$ & 255,73 & 295,88 & 254,43 & 257,98 & 278,79 & 268,56 \\
4 & $150 \mathrm{~m}$ & 204,87 & 215,67 & 211,79 & 209,14 & 227,01 & 213,70 \\
5 & $200 \mathrm{~m}$ & 166,45 & 186,03 & 160,68 & 194,06 & 176,15 & 176,67 \\
\hline
\end{tabular}

Sumber: Data penelitian 2017

Pada seluruh titik/lokasi tanpa barrier tanaman karet kadar debu terendap yang terukur pada titik yang berada di tepi jalan yang hanya berjarak 1 meter, terhitung konsentrasi dust fall tertinggi mencapai 575,05 ton $/ \mathrm{km}^{2} /$ bulan pada P3 dan yang berjarak 200 meter dengan kadar terendah $160,68 \mathrm{ton} / \mathrm{km}^{2}$ / bulan pada P3. 
Tabel 2. Hasil Kadar Debu Terendap Dengan Barrier

\begin{tabular}{cccccccc}
\hline \multirow{2}{*}{ No } & Jarak dari & \multicolumn{5}{c}{ Kadar Debu Terendap (ton/ $\mathrm{km}^{2} /$ bulan) } & Rata-rata \\
& tepi jalan & P1 & P2 & P3 & P4 & P5 & \\
\hline 1 & $1 \mathrm{~m}$ & 568,13 & 517,90 & 566,31 & 536,26 & 525,83 & 542,89 \\
2 & $50 \mathrm{~m}$ & 226,10 & 245,00 & 227,18 & 236,25 & 223,72 & 239,65 \\
3 & $100 \mathrm{~m}$ & 217,60 & 200,21 & 200,85 & 202,62 & 201,39 & 204,53 \\
4 & $150 \mathrm{~m}$ & 142,62 & 199,76 & 141,76 & 177,05 & 150,98 & 162,43 \\
5 & $200 \mathrm{~m}$ & 141,93 & 102,69 & 134,05 & 138,45 & 120,38 & 127,50 \\
\hline
\end{tabular}

Sumber: Data penelitian 2017

Pada seluruh titik/lokasi dengan adanya barrier tanaman karet kadar debu terendap yang terukur pada titik yang berada di tepi jalan yang hanya berjarak 1 meter, terhitung konsentrasi dust fall tertinggi mencapai 568,13 ton $/ \mathrm{km}^{2} /$ bulan pada P1 dan pada titik yang berada setelah barrier yang berjarak 200 meter dengan kadar terendah 102,69 ton $/ \mathrm{km}^{2} /$ bulan pada P2.

Tabel 3. Hasil Penurunan Kadar Debu Terendap Di Sisi Jalan Angkutan

\begin{tabular}{|c|c|c|c|c|c|c|c|}
\hline \multirow[t]{2}{*}{ No } & \multirow[t]{2}{*}{ Jarak dari tepi jalan } & \multicolumn{5}{|c|}{$\begin{array}{l}\left.\text { Penurunan Kadar Debu Terendap (ton } / \mathrm{km}^{2} / \mathrm{bulan}\right) \\
\text { dan Persentase (\%) }\end{array}$} & \multirow[t]{2}{*}{ Rata-rata } \\
\hline & & P1 & P2 & P3 & P4 & P5 & \\
\hline \multirow[t]{2}{*}{1} & $50 \mathrm{~m}$ tanpa Barrier & $\begin{array}{c}266,95 \\
(44,5)\end{array}$ & $\begin{array}{l}298,86 \\
(43,9)\end{array}$ & $\begin{array}{c}258,14 \\
(55,1)\end{array}$ & $\begin{array}{c}260,40 \\
(53,4)\end{array}$ & $\begin{array}{c}289,18 \\
(43,3)\end{array}$ & $\begin{array}{l}274,71 \\
(48,0)\end{array}$ \\
\hline & 50 m dengan Barrier & $\begin{array}{c}226,10 \\
(58,4)\end{array}$ & $\begin{array}{c}245,00 \\
(51,9)\end{array}$ & $\begin{array}{c}227,18 \\
(56,9)\end{array}$ & $\begin{array}{c}236,25 \\
(56,6)\end{array}$ & $\begin{array}{c}223,72 \\
(61,1)\end{array}$ & $\begin{array}{c}239,65 \\
(57,0)\end{array}$ \\
\hline \multirow[t]{2}{*}{2} & $100 \mathrm{~m}$ tanpa Barrier & $\begin{array}{c}255,73 \\
(46,9)\end{array}$ & $\begin{array}{c}295,88 \\
(44,4)\end{array}$ & $\begin{array}{c}254,43 \\
(55,8)\end{array}$ & $\begin{array}{c}257,98 \\
(53,8)\end{array}$ & $\begin{array}{c}278,79 \\
(45,3)\end{array}$ & $\begin{array}{c}268,56 \\
(49,2)\end{array}$ \\
\hline & 100 m dengan Barrier & $\begin{array}{c}217,60 \\
(48,8)\end{array}$ & $\begin{array}{l}200,21 \\
(44,5)\end{array}$ & $\begin{array}{c}200,85 \\
(58,9)\end{array}$ & $\begin{array}{c}202,62 \\
(55,6)\end{array}$ & $\begin{array}{c}201,39 \\
(46,8)\end{array}$ & $\begin{array}{l}204,53 \\
(50,9)\end{array}$ \\
\hline \multirow[t]{2}{*}{3} & $150 \mathrm{~m}$ tanpa Barrier & $\begin{array}{c}204,87 \\
(57,4)\end{array}$ & $\begin{array}{l}215,67 \\
(59,5)\end{array}$ & $\begin{array}{c}211,79 \\
(63,2)\end{array}$ & $\begin{array}{c}209,14 \\
(62,6)\end{array}$ & $\begin{array}{c}227,01 \\
(55,5)\end{array}$ & $\begin{array}{l}213,70 \\
(59,6)\end{array}$ \\
\hline & 150 m dengan Barrier & $\begin{array}{c}142,62 \\
(74,2)\end{array}$ & $\begin{array}{l}199,76 \\
(66,2)\end{array}$ & $\begin{array}{l}141,76 \\
(74,0)\end{array}$ & $\begin{array}{l}177,05 \\
(67,1)\end{array}$ & $\begin{array}{l}150,98 \\
(68,7)\end{array}$ & $\begin{array}{l}162,43 \\
(70,0)\end{array}$ \\
\hline \multirow[t]{2}{*}{4} & $200 \mathrm{~m}$ tanpa barrier & $\begin{array}{c}166,45 \\
(65,4)\end{array}$ & $\begin{array}{l}186,03 \\
(65,1)\end{array}$ & $\begin{array}{l}160,68 \\
(72,1)\end{array}$ & $\begin{array}{l}194,06 \\
(65,3)\end{array}$ & $\begin{array}{l}176,15 \\
(65,4)\end{array}$ & $\begin{array}{l}176,67 \\
(66,6)\end{array}$ \\
\hline & 200 m dengan Barrier & $\begin{array}{c}141,93 \\
(74,4)\end{array}$ & $\begin{array}{l}102,69 \\
(79,9)\end{array}$ & $\begin{array}{c}138,45 \\
(77,8)\end{array}$ & $\begin{array}{c}120,38 \\
(72,6)\end{array}$ & $\begin{array}{c}127,50 \\
(78,8)\end{array}$ & $\begin{array}{l}127,50 \\
(76,7)\end{array}$ \\
\hline
\end{tabular}

Sumber: Data penelitian 2017

Hasil dari persen penurunan kadar debu terendap maka dapat diketahui bahwa terjadi penurunan angka kadar debu tanpa adanya barrier dan naiknya angka dengan adanya barrier.

Berdasarkan hasil penelitian pada lokasi tanpa adanya barrier tanaman karet diperoleh pemeriksaan kadar dust fall pada semua jarak masih melebihi baku mutu lingkungan. Hal ini dapat disebabkan karena kondisi jalan yang dilalui angkutan batubara hanya dengan konstruksi tanah yang dipadatkan dengan campuran batu split dan tidak dilakukan pemeliharaan berupa perbaikan jalan secara rutin, tidak terdapatnya penutup bak truk yang berisikan muatan yang berlebihan, bahkan melebihi dari ketinggian baknya, sehingga ceceran terus terjadi disepanjang jalan angkutan dan tidak adanya vegetasi.

Pusat Penelitian Lingkungan Hidup Universitas Lambung Mangkurat (PPLH Unlam, 2001) Banjarmasin, pernah melakukan penelitian sebaran debu batubara yang termasuk kategori debu melayang (total suspended particulate) di tahun 2001. Hasil penelitian tersebut menunjukkan bahwa sebaran debu melayang dapat mencapai sejauh 529 meter dari sumbernya yaitu jarak sebaran tersebut adalah pada konsentrasi debu 
yang berada di batas baku mutu yang ditetapkan, untuk TSP $230 \mu \mathrm{g} / \mathrm{m}^{3}$.

Kadar debu terendap yang memperlihatkan kecenderungan bahwa konsentrasi debu akan menurun bila jarak terhadap sumbernya bertambah, keadaan ini bersesuaian dengan sifat alamiah debu yang memiliki gaya gravitasi karena adanya gaya berat. Gaya berat debu ini berhubungan dengan jenis/macam debu dan ukuran partikelnya.

Berdasarkan hasil penelitian pada lokasi dengan adanya barrier tanaman karet diperoleh hasil pemeriksaan kadar dust fall pada semua jarak masih melebihi baku mutu lingkungan. Hal ini dapat disebabkan karena faktor penyebab yang sama pada daerah tanpa barrier. Namun pada pemeriksaan dengan adanya vegetasi, maka kadar debu terendap semakin kecil kadarnya dan pada setiap variasi lebar lanskap menunjukkan penurunan kadar debu terendap lebih tinggi dibandingkan dengan tanpa barrier. Dengan adanya vegetasi maka debu akan menempel pada permukaan daun dan permukaan tanaman dibuktikan dengan kotornya daun pada vegetasi.

Hal ini sejalan dengan penelitian Irwan (2005) dalam Inayah (2010), Surjamanto (2009), Tahuttu (2001) dan Sianturi (2012) bahwa vegetasi sangat bermanfaat untuk merekayasa permasalahan lingkungan salah satunya untuk mengurangi konsentrasi kadar debu. Dengan adanya vegetasi, debu dan abu akan terjerap (menempel) pada permukaan daun, yang disaaat hujan akan tercuci oleh air hujan. Kemampuan pembersihan encemar partikel juga dipengaruhi oleh kepadatan vegetasi dan struktur kerimbunan dedaunan, semakin rapatnya jarak antara vegetasi maka kelembaban makin tinggi dan suhu akan menjadi rendah.

\section{KESIMPULAN DAN SARAN}

Berdasarkan hasil penelitian tentang pengaruh lebar lanskap tanaman karet terhadap kadar dust fall di sekitar jalan angkutan batubara di peroleh simpulan bahwa kadar debu terendap tanpa perlakuan tertinggi berada pada jarak $1 \mathrm{~m}$ dari sisi jalan yaitu 575,05 ton $/ \mathrm{km}^{2} /$ bulan dan yang terendah pada jarak $200 \mathrm{~m}$ dari sisi jalan yaitu 160,68 ton $/ \mathrm{km}^{2} /$ bulan dengan baku mutu yang hanya 10 ton $/ \mathrm{km}^{2} /$ bulan. Sedangkan pada jarak $200 \mathrm{~m}$, kadar debu juga masih berada di atas baku mutu lingkungan (menurut PPRI No. 41 Tahun 1999). Kadar debu terendap dengan perlakuan tertinggi berada pada jarak $1 \mathrm{~m}$ dari sisi jalan yaitu 640,20 ton $/ \mathrm{km}^{2} /$ bulan dan yang terendah pada jarak $200 \mathrm{~m}$ dari sisi jalan yaitu 102,69 ton $/ \mathrm{km}^{2} /$ bulan dengan baku mutu yang hanya 10 ton $/ \mathrm{km}^{2} /$ bulan. Sedangkan pada jarak $200 \mathrm{~m}$, kadar debu juga masih berada di atas baku mutu lingkungan (menurut PPRI No. 41 Tahun 1999).

Faktor-faktor yang mempengaruhi kadar debu dengan jarak di antaranya adalah faktor meteorologi yaitu suhu dan kelembaban, sumber debu, transportasi, faktor lingkungan dan faktor fisik. Upaya perusahaan dalam menanggulangi disperse debu di sekitar jalan angkutan batubara dengan melakukan penyiraman di sekitar jalan yang dilewati angkutan batubara, dengan penyiraman dilakukan sekitar 16-24 kali penyiraman jalan, namun penyiraman jalan ini tidak merata dalam 24 jam dan tidak merata pada lintasan angkutan, sehingga pada jam-jam tertentu tidak terjadi penyiraman. Dari uji statistik menunjukkan terdapat pengaruh perbedaan kadar debu terendap baik pada lokasi tanpa barrier maupun lokasi dengan barrier terhadap masing-masing jarak.

Bagi perusahaan batubara agar melakukan penyiraman badan jalan dengan intensitas kebasahan yang cukup dan merata dilakukan selama 24 jam, pemeliharaan jalan angkut berupa perbaikan jalan secara rutin, pengelolaan transportasi dengan membuat penutup pada bak truk yang berisi batubara agar tidak berceceran pada saat melewati jalan angkut batubara, dan melakukan penanaman pohon yang mampu menjerap dan menyerap partikel debu lebih banyak.

Untuk penelitian selanjutnya agar menambahkan lagi jarak agar didapatkannya hasil yang lebih rendah dari baku mutu lingkungan, dapat mengetahui suhu 
dan kelembaban pada masing-masing titik.

\section{KEPUSTAKAAN}

1. Junaidi. (2016). Kajian Konsentrasi Debu Dari Jalan Khusus Angkutan Batubara Dan Risikonya Terhadap Kesehatan Manusia Dan Tanaman Karet Di Kabupaten Tpin. Tesis. Universitas Brawijaya. Malang.

2. Notoatmodjo, S. 2012). Metodologi Penelitian Kesehatan. Rineka Cipta. Jakarta.

3. Pusat Penelitian Lingkungan Hidup. (2001). Universitas Lambung Mangkurat Banjarbaru.
4. Sianturi, R. (2012). Pengukuran Suhu Dan Kelembaban Udara Di Berbagai Vegetasi. Agribisnis. Fakultas Pertanian Universitas Jambi.

5. Surjamanto, Waworahardjo. (2009). Studi Pengaruh Kualitas Vegetasi Pada Lingkungan Termal Kawasan Kota. Institut Teknologi Bandung. Bandung.

6. Taihuttu, Hermina Neltje. (2001). Studi Kemampuan Tanaman Jalur Hijau Jalan Sebagai Penjerap Partikulat Hasil Emisi Kendaraan Bermotor. Tesis. Institut Pertanian Bogor. 
